\title{
The Redundant Researcher: Fieldwork, Solidarity, and Migration
}

\author{
Vasilis Galis
}

\section{INTRODUCTION}

"A 24-year-old man from Cameroon was found dead inside the Moria migrant camp on the eastern Aegean island of Lesvos early Tuesday morning [...] as temperatures fell below freezing" (Athens-Macedonian News Agency 2019; The Guardian 2019). These were the headlines that I was confronted with four days before my arrival on Chios and Lesvos, the two major islands in the north-east Aegean Sea, at the sea border separating Greece and Turkey, hosting thousands of migrants attempting to reach Europe. I was about to launch my fieldwork, interviewing migrants about their digital practices regarding the European border regime within the framework of the DIGINAUTS project. These were also my first tentative steps concerning research fieldwork that was both new and hostile to me. Migration studies constitutes a rapidly growing field resulting in what Casas-Cortes et al. $(2015,63)$ call a "migration

V. Galis $(\bowtie)$

Center for Digital Welfare, IT University of Copenhagen, Copenhagen, Denmark e-mail:vgal@itu.dk

(C) The Author(s) 2022

M. Sandberg et al. (eds.), Research Methodologies and Ethical Challenges in Digital Migration Studies, Approaches to Social Inequality and Difference, https://doi.org/10.1007/978-3-030-81226-3_7 
knowledge hype". While I was struggling to find my space in the field, without being part of the hype, Greek governmental sources leaked that the causes of death of the young Cameroonian mentioned above were unknown. However, local self-organised solidarity groups, such as the No Border Kitchen, were very clear:

On January 8, 2019 the European Border regime, and violent neglect of human life and dignity present in Moria camp on the Greek Island of Lesvos led to the death of Jean Paul, a 24-year-old man from Cameroon. The last few weeks have been the coldest ones yet this winter, with temperatures hovering around freezing, high winds, and frequent rainstorms. Much of Moria has been experiencing power outages for days, leaving many people without heat and other basic necessities. (No Border Kitchen 2019)

Already before I left Athens, I had a banal sense of doing something terribly wrong. Who am I, with my White academic privileges, to approach entrapped migrants in the trench of Fortress Europe and talk to them about their use of digital applications? How can I justify, first to myself, politically and even academically, the fact that I was seeking to ask questions about mundane and trivial experiences, while people were literally freezing to death? What is this research about and for whom is it relevant? This chapter is not an answer. This chapter poses questions. What is it like to conduct academic research on a phenomenon that is polluted by vested political interests, personal tragedies, ideological loyalties, propaganda, and hazards for the subject of research or on a subject of research in danger? How is this kind of fieldwork compatible with my ideological integrity? Is it possible to do research that contributes to migrant struggles? Am I performing action research, or just building my career?

The aim of this chapter is to reflect on and investigate the possibility of conducting migration research that contributes to the freedom of movement and safety of mobile populations, while reflecting on the emotions and political loyalties of the researcher (see also Fischer and Bak Jørgensen, Chapter 6 in this volume). This chapter also aims to contribute to the epistemological/methodological debate on migration studies by suggesting concrete principles for an emancipatory migration research paradigm, building on the combination of disability studies and the Autonomy of Migration (AoM) approach (for an introduction to the AoM approach, see Chapter 6). To accomplish that, I will first 
relate personal experiences and emotions, reflections, and narrations by migrants and solidarians ${ }^{1}$ during and after qualitative fieldwork on the Greek islands of Lesvos and Chios in the winter of 2019. These experiences, emotions, reflections, and narrations are "constricted by the historical context in which they are made" (Nordstrom and Robben 1995). This period was almost four years after the 2015 so-called "long summer of migration" when a large migratory influx reached the European borders, with mainly newcomers from Syria. Thousands of migrants were entrapped (and still are) in open and closed detention centres or hotspots $^{2}$ in the Greek islands, the EU-Turkey Statement ${ }^{3}$ was in force, and a wave of anti-migration voices and false information spreading through social media and other digital sources had taken over the public debate both in Greece and internationally (Farkas et al. 2018; D'Haenens et al. 2019; Titley 2019). In the same period, both the Greek state and mainstream media launched a whisper campaign against solidarity with migrants. NGOs and self-organised collectives were criticised, accused, and discredited by government officials and reporters/journalists who sympathised with the regime (Fekete 2018; Rozakou 2017, 2018; Gordon and Larsen 2020).

An extended network of solidarity, comprising mainly political actors from the extra-parliamentary spectrum, was initiated to welcome the newcomers, confront racist and xenophobic behaviours, and accommodate migrants during their temporary or permanent stays in Greece. These activists and solidarians voiced scepticism to researchers and academics visiting the islands to conduct research on the recent flows of migrants. Questions arose about who would benefit from this research, in what ways the mobile subjects would be supported by the academic research, what constitutes action research, and whether there is a risk that we all fall into the trap of action research washing. Given that a good part of migration research supports policy (Black 2001) and that my research agenda did not aim to provide any policy recommendations, doing fieldwork resembled a political, ideological, methodological, and epistemological minefield, with every step signalling a warning in all kinds of directions. I was about to conduct research on vulnerable migratory subjects exposed to physical and structural violence, issues of trust and power asymmetries between the researcher and the researched were prominent, and my own ideological/political concerns as well as emotions were kicking in. What a mess! In the following, I outline my research stays at the islands of Chios and Lesvos. The description of the fieldwork will be 
enhanced by reflections and concerns that emerged while conducting the research. I then translate these concerns into a concrete set of principles for conducting emancipatory migration research, inspired by disability studies. The chapter will conclude with a final reflection on conducting politically engaged research.

\section{Arriving on the IsLANDS: From EMOTIONS of Scepticism to Holistic Shame}

Despite my long-lasting aerophobia, I took the early flight from Athens to Chios on 12 January, which took almost 30 minutes. I soon realised that I was making the same journey as many migrants dreamed of making but in reverse and in the most convenient and less time-consuming way, instead of spending hours on a boat in the middle of winter. I was travelling from the Greek mainland, a European capitol, and one of the first urban stops for migrants, to the north-eastern islands on the border with Turkey. There I was, with my European mobility and class privileges, travelling safely, fast, and comfortably to one of the epicentres of modern migratory drama, where thousands of people were literally trapped in camps, detention centres, and hotspots under horrific conditions in terms of hygiene, weather, and freedom of mobility. On reaching Chios, I was welcomed by an old colleague of mine who showed me around and made sure I would experience the finest of the local cuisine. The emotional roller coaster was about to begin-and was not to be underestimated. Even in the literature on reflexive research practice, emotions tend to be overlooked (Gray 2008). Therefore, I turn to feminist and queer epistemologies that have problematised researchers' own reflections on dealing with emotions, not only as an impact on the researched or the research agenda, but also on themselves (Van Liempt and Bilger 2009). Following Ahmed (2014, 4), dealing with emotions in research practice and about the research subject "is clearly dependent on relations of power, which endow 'others' with meaning and value". My privileged position and ability to move on Chios seriously impacted my feelings for my fieldwork and ascribed vulnerability to the migrants. My subject position was co-constructed by my emotions and scepticism regarding my research but also through the experience of vulnerable populations detained in a huge hotspot surrounded by water. I will return to the concept of vulnerability later.

My first hours on Chios were impregnated by strong scepticism and a feeling of personal shame, reflecting on the asymmetries between my 
subject position and the migrants whom I was about to meet. What on earth was I doing here? How would I be able to find and talk with migrants living in inhuman conditions about mundane digital practices while I was enjoying my host's hospitality, my freedom of mobility, and the warmth of my hotel room? How could I convey that to my political circles? Is it possible to separate research (work) from political standpoints and my own situatedness? It was impossible for me to conceal or separate my emotions from my way of thinking or even the way I was conducting my fieldwork. Gray (2008) argues that academic inquiry is concurrently an embodied, emotional, and political activity, and therefore emotions also partake in knowledge production. In that sense, my emotions also reflected my standpoint on the world, or how I am apprehending migration issues in general, not merely as a researcher or a politically active subject, but as a whole. Through my emotions, I reacted to the contradictions I faced upon arriving on the islands. This was not a martyr's act of self-flagellation, but rather a realisation of how "I" and "we, the research community" are shaped by our contact with the ontologies of migrants. In that sense, these kinds of emotions also involve politics, since they constitute reactions to how power relations enact our fieldwork ontologies and bring epistemological attention to how we, as researchers, become invested in specific issues (cf. Ahmed 2014). But is this enough? Will sharing these reflections and emotions in another academic paper accessible to a specific readership and using sophisticated literature make any difference, and to whom?

My first couple of days on Chios were spent on developing a snowball effect to find relevant informants for the study. The target groups were migrants and solidarians who were keen on using digital media or hosted websites, social media accounts, or other self-organised media, which facilitated solidarity with mobile populations and produced practical information. To do that, I employed my local contacts and acquaintances, especially through my colleague who lived on the island, and my efforts were quite successful. For reasons of ethical and political integrity, I consciously avoided contacting people whom I knew through political activity related to solidarity work with migrants, but soon realised that separating worlds would be impossible. Although I wanted to avoid mixing up these categories, the reality of the fieldwork brought together myself (as a researcher), solidarians whom I perceive as political comrades, migrants involved in solidarity projects, and therefore politicised, and 
myself (as a conscious political subject). How could it be possible otherwise? My subject positions constantly changed, oscillating between an anticipated academic distance that many epistemological traditions require (neutrality I believe it is called) and my political engagement (partiality). ${ }^{4}$

What I felt was shame, a feeling of corrosive shame and betrayal for performing a research role in a heavily politicised field with which I usually practiced solidarity. My reflections on university careers, elitist academic research detached from the actual needs of migrants on the move, redundant research questions or problems concerning the hardship of living detained in tents in the middle of winter, and many other critical thoughts dominated my thoughts. Ahmed (2014) argues that shame prevents the individual from betraying ideals, while the lived emotion of shame makes the individual understand and appreciate the reasons for adopting these ideals in the first place. Feeling shame is a manifestation of failing to achieve these social ideals but it also allows us to reflect on and come closer to what we are failing to accomplish. According to Ahmed, the feeling of shame can be restorative if it is temporary because "shame binds us to others in how we are affected by our failure to 'live up' to those others, a failure that must be witnessed, as well as being seen as temporary, in order to allow us to re-enter the family or community" (ibid., 107). I struggled and kept struggling to find the restorative element in feeling shame during my fieldwork and the ways to bridge research with my political situatedness. Is this even possible? I will return to that.

\section{Fieldwork or Minefield? Reluctant Trust, Vulnerabilisation, and Political Solidarity}

When the interviews began, I faced the raw reality of migrants being entrapped on an island in the middle of winter. I talked mainly to young males with different backgrounds, ethnicities, and sexual orientation. These interviews were emotionally and empirically strong, touching upon mundane aspects of everyday life in the detention centres, the hotspots, and on the island in general through the lens of digital media usage. It was obvious that the use of smartphones and social media played a vital role in the well-being of migrants as well as posing a threat for a variety of reasons, which are not part of the scope of this chapter. However, this meant that conducting this particular fieldwork was not as redundant as I had thought from the outset. My informants were very eager and open about discussing their digital habits and found it amusing to show 
me different applications as well as tricks they employed to gain internet access. This made me immediately concerned. Suddenly, I had access to sensitive information about closed social media groups, methods to safely cross the borders, secure chats, tricks on how to use the smartphone, ways to acquire SIM cards, and so on. This was not a problem in terms of the privacy of the migrants themselves or their protection. I was perfectly aware of the sensitivity of the material and ways to protect it or omit it from my empirical storage. I turned off the recorder when sensitive information was communicated and/or I excluded from the transcription or the analysis knowledge that could harm my informants. ${ }^{5}$ What worried me and made me reflective was the ease and trust that these people showed me. Usually, simply the word "research" might create mistrust and raise suspicion among informants.

The common issue in research situations like this is how to build trust and to invest time in establishing personal contacts with possible respondents (Van Liempt and Bilger 2018). I experienced exactly the opposite phenomenon. Due to my personal acquaintances and my political involvement (which was not consciously activated to create the snowball effect, but did make a difference after all), I was granted access to a large group of migrants (and solidarians) who were eager to openly talk to me about their personal encounters with digital media, describing in detail important and sensitive information. The feeling of shame and bad conscious dramatically returned. What do I give back to my research informants? Being conscious of the power asymmetries, me with my academic and European privileges collecting material on their digital habits and furthering my research agenda, and migrants in their vulnerable positions entrusting me with their information capital, for what?

Things became even more complicated when some of the informants wanted to be friends with me on social media, which I did not decline. Within a few hours of the interviews, I received several messages with various content: from friendly discussion to asking for help and money to legal advice. It was obvious that my informants perceived me as a person who could help them improve their position due to my intersectional subject position (see also Düvell et al. 2010). Right there, the power asymmetries were visualised and concretised in various texts in Messenger. Several questions arose: how did the way they perceived me influence what they told me? How should I assess the quality of information, given that the subject is in a vulnerable position? What should my role be, not as 
a fragmented (sometimes a researcher, sometimes an activist, sometimes neither) subject but as a whole, to their requests whatever these were? Was it wrong of me to digitally connect with these people? Wrong for whom and for what? Was it politically, socially, or research-ethically wrong? According to Van Liempt and Bilger $(2018,278)$ "researchers in this field must be aware that the relation between the researcher and the respondent, even if trustful and close, is not equal and is clearly influenced by inequalities of rights, legal and economic position, gender and/or psychological position". What if the researcher refuses her one-dimensional role and reflects on her pluralist subject? What happens then to the quality of research or the political activity? These are issues that, along with feminist theory, anthropology, and more (e.g. Clifford and Marcus 1986; Foley 2002; Venkatesh 2013), I will problematise in the next two sections. Ahmed (2014) again explains that the swarm of emotions partaking in the research process shape interaction with informants and create boundaries for the research subject. These emotions "produce the very surfaces and boundaries that allow the individual and the social to be delineated as if they are objects" (ibid., 10). In that way, my pluralist subject position also populates the epistemological arena of my research and colours my interpretation of the social in terms of migration and political solidarity.

What made me additionally concerned was the fact that I constantly experienced my informants as in a vulnerable position. Staying true to the idea and practice of solidarity, ${ }^{6}$ the "vulnerabilisation" of migrants, either by my own feelings or by their given situation, gave me a sense of unease. According to Lind (2020, 45), vulnerabilisation comprises "the processes (in the context of migration and beyond) of constructing, attributing and governing vulnerability". Did I (a White, middle-class, heterosexual cisgender man), or my research, constitute my informants as vulnerable? While Lind refers to how specific migratory groups should be attended to, cared for, or governed, I reflected on my own concern regarding how the contradiction between humanitarian empathy and collective solidarity works to oppose the structural racism and violence that moving populations face upon arrival at Fortress Europe. In other words, conducting fieldwork in this case activated a feeling of superfluousness and powerlessness on my behalf that automatically turned my informants into vulnerable subjects worth of empathy. In addition, some of the interviews were strong enough to trigger distressing memories among the informants. I, a western researcher, collected stories and narratives about forced migration, war, abuse, loss and grief, survival, 
and forms of violence that non-western people had experienced. I found myself in a situation where my informants were affected by recalling and reproducing painful dimensions of their lives and I oscillated between emotions of (humanitarian) empathy and my values of political solidarity.

By this I mean that in this context, I perceive solidarity as a horizontal coalition of migrants, activists, and local people, leading to a series of actions that place migrants' desires and passages at the heart of the action, instead of framing migrants in humanitarian terms of being victims and vulnerable. I could not find myself in the humanitarian responses to global oppressions through gestures of compassionate hospitality (see also Tyler 2006; Millner 2011) or the human rights discourse. In the western liberal narrative, someone who is worth rights, empathy, help, charity is someone innocent, good, exposed to harm. There is an element of purity in the vulnerable subject (see also Ticktin 2017). It is almost a Christian theological thesis that impregnates the western human rights discourse. Lind (2020), following Arendt (1951), explains that human rights rely on citizenship and on belonging to a community that attributes rights. This is a political and not a humanitarian issue. Turning to human rights and a humanitarian approach constitutes an act of depoliticisation (Ticktin 2014) through delegating solidarity with migrants to state and institutional charities. Charity is the humanitarian mask behind the face of economic exploitation (Žižek 2008, 19). This also implies recognition of formal systems of classification that divide moving populations into economic migrants, refugees, asylum seekers, deportable, legal and illegal individuals, and so on (see also Jørgensen 2012; Lundberg and Söderman 2015).

In the context of the liberal state, the human rights discourse, humanitarianism, and philanthropy maintain the power hierarchies between those who have rights and those who claim rights, and the administrative and statistical distinction between those included and those excluded from the privileges and rights provided by the nation-state. Vandevoordt (2019) explains that, as human rights providers or beneficiaries are perceived to acquire resources, power, and expertise, human rights receivers are reduced to vulnerable individuals in need of being fed, cared for, and represented by others. In the context of my fieldwork, the increasing criminalisation of self-organised solidarity work by the Greek authorities and the "NGOification of solidarity", meaning the normalisation and assimilation of grassroots solidarity by professional and institutionalised international humanitarian organisations, added another element of 
antagonism between humanitarianism and grassroots solidarity (Rozakou 2017).

My understanding is that engaging with migration issues implies a politics that sides with minorities, the stateless, the powerless, the undocumented, the "undesirable" migrants, those who are not protected by the constructed state borders and territorial lines (see also Honig 2009; Millner 2011; Lind 2020). The vulnerabilisation of my informants, through the research process, belonged to a discourse and practice that were alien to me. One of the pertinent questions that arose for me during my fieldwork on Chios was how political solidarity, in the terms described above, can be compatible with academic research that cannot only be considered redundant but also may create emotions of shame as well as "vulnerabilising" the research subject. Düvell et al. (2010) argue that (migration) researchers are primarily not activists but academics and they are responsible for high-quality and ethical research, their subjects, their profession, their funders, and so on. For the readers who side with the latter and adopt a symmetrical or neutral epistemological research standpoint, I would respond that all research is partisan. This constitutes a step beyond the dualist epistemological dilemma of modernism, that is, being epistemologically objective about a responsible and valuefree science versus being epistemologically objective about an ethically engaged science (Galis and Hansson 2012). The issue here is what kinds of emotions and subject positions the research process enacts and how these partake in the constitution of the researcher's subjectivity and/or how they become (in)compatible with what is called solidarity in radical political terms or "shared conversations" in epistemology (cf. Haraway 2001, 176). Therefore, and given the partiality of all actors involved in migration research, the challenge for me here was to substitute or convert the emotion of shame into epistemological and political solidarity with the migrants.

I left Chios with these paradoxical reflections, taking the night boat to Lesvos. It was a rainy night and the first impression I had while waiting to embark from the boat at the port of Chios was of a few military vehicles disembarking the huge vessel that had just arrived from Piraeus. This image of an interwar period immediately reminded me that I was not only situated, politically and geographically, at the heart of a contemporary migratory drama but also at the borderland that signifies the diachronic low-intensity cold war taking place between Greece and Turkey. This was also the scene met by thousands of migrants who had 
left their countries to escape the adversities of war, violence, and poverty. They were not only confronted with the structural violence embedded in bordering practices and migratory policies, but also the visual and mundane violence projected on military technologies and troops guarding the Greek sovereignty. In line with Nordstrom and Robben (1995), the most pressing reality of ethnographically studying populations exposed to violence is the sociopolitical violence prominent where civilian populations are located, such as in camps and hotspots, and in the sociotechnical processes, sceneries, and mundane practices where these populations live and to which they are exposed. My fieldwork also covered violence.

\section{Lesvos: "Hell on EARTH"}

More than 12,000 people - mainly from Syria, Afghanistan, and Iraq - live in Moria camp, which has grown to become the island's second largest town in just three years. The woman's death on Sunday was the third there in two months. An Afghan teenager was killed in a fight in August and a fiveyear-old Afghan boy was accidentally run over by a truck while playing in a cardboard box outside the camp in September. Holding signs reading 'Moria is hell' and 'We want security and freedom', the protesters were prevented from marching farther than a few hundred metres (yards) from the camp's gates by around two dozen riot police. Moria, in a former military base, opened in 2015 as a centre to register new arrivals but is now at four times its capacity and it has spilled over into a muddy, garbage-strewn olive grove. (Reuters 2019)

The excerpt above from an international mainstream corporate media, such as Reuters, is indicative of the violence that migrants are exposed to in the camps established by the Greek government with the financial support of the EU. Moria, on Lesvos, was one of Greece's largest migrant camps. There are several others in the Greek islands and mainland. Arriving on Lesvos made me realise that the whole island resembled a huge camp or rather a prison for migrants. Migrants living in extremely poor conditions, people dying due to extreme weather conditions, ethnic violence among migrant groups, sexist violence against sexual minorities, racist violence against migrants by local nationalists, structural violence against the newcomers by national authorities, and the European border management apparatus constituted my fieldwork. Moria, and Lesvos in general, is not a hotspot, a migration camp, a reception centre. I could 
not stop thinking of Andrea Pitzer's (2017) description of camps: “camps have been in existence continuously somewhere on the globe for more than a hundred years. Barracks and barbed wire remain their most familiar symbols, but a camp is defined more by its detainees than by any physical feature. A concentration camp exists wherever a government holds groups of civilians outside the normal legal process - sometimes to segregate people considered foreigners or outsiders, sometimes to punish" (ibid., 5, emphasis mine). The organisation of social and mundane life on the islands segregates the local population from newcomers, who are not free to move around or leave the islands.

As on Chios, I spent the first couple of days on Lesvos initiating a snowball effect to identify relevant informants. I talked to young male migrants from Palestine, Iraq, and Cameroon as well as solidarians from Spain and Greece. Most of the migrants I talked to had left their countries of origin because of war and poverty as well as exposure to sexist violence because of their sexual orientation. Even their descriptions of their use of smartphones and social media included an element of violence. Some of them avoided dating applications in their home countries or along the journey for fear of surveillance and suppression. Certain forms of sexuality were illegal in their countries or in transit. Others described how they were receiving threats in digital forums from co-patriots or members of other ethnic groups while on Lesvos. A few of them even described incidents of abuse on Lesvos or the violence in the Moria camp (including a minor insurrection that led to part of the camp being burned down ${ }^{7}$ ) that they were afraid to post about on their social media in case the authorities found out. Taking pictures or videos inside the camp and spreading them was banned. That would obviously harm the humanitarian face of both the Greek state and the EU. The most shocking descriptions, however, were those concerning the use of smartphones and social media while being at sea, crossing the Aegean to reach Lesvos in small rubber boats that often sank. These dramatic narratives referred to moments of desperation and survival while migrants tried to maintain online contact with solidarians at the other end of the phone who were navigating the trip at sea and whom they could call for help if needed. I was told about parents who lost their children, brothers who lost their sisters, children who lost their mothers in the huge graveyard of the Aegean Sea.

Again, I found my research role rather redundant in this setting. Anthropologist Gayatri Spivak (1988) questions the motives and sincerity of western researchers in studying non-westerners exposed to power 
asymmetries and violence unless they go through a self-critical questioning not only of their research role but also their cultural subjectivity as historical products of specific privileges (see also Nordstrom and Robben 1995). Is this the purpose of this text? What does reflection mean in the context of the violence and incarceration that my informants are exposed to and how does it make my research sincere and motivated? How many of my informants will actually read these lines and how will this text make a difference to their everyday life? No matter our academic dedication, even to what we have coined as action research, we cannot avoid the legacy of our privileged position and hegemonic culture (cf. Nordstrom and Robben 1995). The structural and material violence that migrants are subjected to is not simply a case of western arrogance or cruelty. They are exposed to the obscene underside of our privileged western culture, which at the same time acts as the necessary supplement to a liberal understanding of dignity, freedom, mobility, and citizenship. The exception proves the rule. And what is the semiotic load of scientific inquiry in this? Does research provide any social change for migrants or does it perpetuate, in a critical way, of course, the very core of the European border regime that sustains Fortress Europe?

In the final days of my stay on Lesvos, I conducted interviews with a couple of solidarians. Their descriptions were vivid and sober, slightly distant from the experiential narratives of the migrants. However, the element of violence was also dominant. They provided me with short and contemporary historiographic accounts of the solidarity movement on the island and how it diachronically dealt with the systemic violence inherent in the border regime. The solidarians also described the agony and traumatic experiences that migrants experienced in captivity or upon arrival or during their stay in the island. It was obvious that it was not the first time they had talked to researchers and journalists. My political background motivated them to talk to me, despite their disillusioned approach to academic research and mainstream journalism. They had no expectations or hope that once more telling the story of how Lesvos has turned into a living hell for migrants would make any difference. This was common knowledge by then, and several scholars and journalists (see, for example, the New York Times 2018; Al Jazeera 2018; Deutsche Welle 2019; The Guardian 2020; Balouziyeh 2017; Colson 2017) had written about the issue without any profound changes or interventions to improve everyday life for the migrants. This made me think of Hannah Arendt's (1972, 132) words: “the ceaseless, senseless demand for original 
scholarship in a number of fields, where only erudition is now possible, has led either to sheer irrelevancy, the famous knowing of more and more about less and less, or to the development of a pseudo-scholarship which actually destroys its object". The aim of the DIGINAUTS project that I was part of was to highlight how migrants' widespread, varied, and innovative digital practices remake migration and potentially create networks of solidarity as migrants navigate through the European border regime. How relevant was this issue and to whom? If social scientific fieldwork is characterised by a combination of empathy and detachment (Robben 1995), who would benefit from conducting scholarship in this field, and what impact would I have on the subject/object of the research?

I have two choices here. Either to sink into this bottomless academic/existential fatalism that scorns my research and academic research in general. Badiou (2004) provocatively states that "it is better to do nothing than to contribute to the invention of formal ways of rendering visible that which Empire already recognizes as existent”. Žižek (2008), building on Badiou, goes one step further, discouraging scholars from engaging with debates and research that allow the system to run more smoothly. Or to choose not to stay inactive and to move the research agenda beyond a vulnerabilisation framework and an internal academic self-confirming that builds professional careers and enhances the intellectual debate with "fascinating" empirical material and flashy theoretical concepts. After all, "researching other people's sufferings can only be justified if the research explicitly aims at alleviating that suffering" (Turton 1996, 96). Lind (2020), in describing his epistemological and methodological standpoint while writing his doctoral thesis, argues for research that can contribute reciprocal benefits that include its participants, such as "taking responsibility as an activist researcher for presenting analyses that highlight injustices and hopefully make social change in a more democratic and inclusive direction possible" (ibid., 83). Pittaway et al. (2010) propose a method of working with vulnerable populations in an anti-oppressive way, despite the subject position imbalances. Van Liempt and Bilger (2018) call for subject-centric methodological approaches in research fields, such as those of migration studies. For me, this implies developing a research agenda that takes responsibility for social interests in the production of knowledge and deconstructs powerful 
actors such as the state, the law, the border, and orthodox approaches to research.

This agenda must openly resonate with the research subject and how the research subject ought to participate in the configuration of the research work and its implications. We need to return to our informants, in whatever form possible, the information and cognitive capital that they generously offer us. In the context of migration research and border studies, I do not suggest another policy discussion or recommendation concerning the democratisation of institutional processes and the border regime. Along with Lundberg and Strange (2017), I aim towards a "postinstitutionalist" take on migration politics and human rights that departs from the importance of everyday acts in providing a political grounding for migration-related research. In that sense, I believe that borders are vectors of specific politics that cannot be subject to democratisation. I argue in favour of methods and a research epistemology that reconstitute social relations between the researcher and the researched, the subject and the object.

Inspired by the Autonomy of Migration (AoM) approach, I want to contribute a methodological framework "that prioritizes the subjective practices, the desires, the expectations, and the behaviors of migrants themselves" (Mezzadra 2011, 121), not as in a romantic and idealist approach to migration studies methodologies, which often implies empty buzzwords that scholars tend to use in ambitious and action-oriented research projects. In line with Fujimura (1991, 223), I “want to take stands, to take points... I want to construct concepts and theories to help some people win over others". I want to implicate my subjectivity and my methods in the epistemological realm of my research and therefore participate in the presentation, management, and politicisation of the topic under investigation (see also Mackenzie 2012). This does not constitute a methodological invention by any means. Several fields have reflectively recognised the participation of research subjectivities in research (Marres 2012). My aspiration here is to go beyond the recognition of my own situatedness. I am interested in systematising the ways that method can actively engage with the research outcome. I want to explore the potential of methods to "contribute to the framing of change" (Lury and Wakeford 2012). The question then becomes, how do our methods intervene, interfere, and/or refract in the knowledge-producing debates of which they are part? 


\section{BACK to ATHENS: Towards AN EMANCIPATORY Migration Research Paradigm?}

I took the late afternoon flight from Lesvos to Athens. My forehead was hot, and I felt dizzy, not only because of the epistemological and methodological riddle overwhelming my mind. I had caught a serious cold that reminded me that soon enough I would return to the comfort and ease of my apartment in Athens in contrast to most of my informants, who would continue dwelling in the cold tents in the Moria camp or wherever they were located. I would spend the next couple of days in bed trying to recover from a regular flu, which gave me plenty of time to reflect and organise my thoughts around the issues thoroughly described above. This translated into a concrete idea to contribute to the valuable AoM approach with a concrete vocabulary and set of methodological actions that may assist the struggle of migrants for emancipation, free mobility, and open borders. Casas-Cortes et al. (2015) explain that politically engaged investigation in migration studies has two main tasks. Firstly, to identify and analytically and politically support contested politics with which migrants engage, the conflicts and ruptures that migration practices cause, migrants' strategies to enable all kinds of movement, and the migrants' experiences. Secondly, to reshuffle the epistemological standards of migration research methodology by turning migrants into subjects rather objects of research, management, care, advocacy, and so on and by simultaneously removing the status of migration researchers as advocates who speak for, activist scholars and scholar activists who act on behalf of others. Accordingly, one of the main demands I made of myself was to refrain from developing an epistemological and methodological toolkit stemming from my own subject position, the western privileged white, cis-researcher. How could I avoid the pitfall of becoming an avant-garde translator/interpreter of migrants' needs, ideas, and will in the research sphere? For many years, I have worked and researched within disability studies. At the start of the 1990s, disability scholar Mike Oliver coined the term emancipatory disability research to introduce a radical new approach to researching disability. Oliver (1992), a disabled person himself, suggested that disability researchers must interact with disabled people and their organisations on a regular basis and must enlist their knowledge and skills at the disposal of disabled people for them to use in whatever ways they choose. Could this be translated into migration research? This will be a modest attempt. 
There is a long tradition of participatory research methodologies within disability studies. However, these kinds of methodologies have a normalising nature. For instance, the growth of participatory approaches with people who have learning difficulties has been dominated by the rhetoric of normalisation and community care (French and Swain 1997). Similarly, migration studies has been dominated by a normalising governance discourse, enforced by an allegedly politically neutral methodological format through migration narratives, policy mobility frameworks, and technical contributions. In that way, "research protocols in migration studies are standardized and reconstituted as objects of disciplinary investigation and the political and social stakes involved in migrant advocacy are 'professionalized' and diluted" (Casas-Corteset et al. 2015, 63). This is not my intention. I oppose the normalising discourses of the integration of migrants in the western labour market and/or culture as well as technologies and policies of migration management and control. I am sceptical of standardised research protocols that perform politically "neutral" inquiries and contribute sound policy recommendations.

The emancipatory disability researcher engages in political action by changing the relationships involved in research production, i.e. the power relationship between researchers and the researched. Emancipatory research, within disability studies, stems from the politics of the disability movement and aligns with the social model of disability, which perceives disability not as a medical entity or an individual problem, but as a social and political issue that permeates disabling infrastructures and cultures. One can argue that emancipatory disability research is not a research methodology as such, but rather another political instrument at the disposal of disabled people in their struggle to control decisionmaking processes that shape their lives, to counteract societal and cultural biases, to intervene in the built environment, and co-produce accessible infrastructures (see also Galis 2006). In that sense, I see similarities with the conceptual framework of the AoM approach that views migration not primarily as a phenomenon defined by state power or the discourse on sovereignty but rather as a political and social movement itself (De Genova 2017). An emancipatory methodological toolkit in line with AoM should then enable and encourage migrants to configure the research agenda.

Specifically, a major characteristic of emancipatory research is the insistence that migrants should control (rather than merely participate in) 
the entire research process from the formulation of the research question to the dissemination of the findings. Researchers are thus at the service and under the direction of people on the move who are no longer "the researched" but rather co-researchers and managers of the research. Emancipatory research adopts the AoM approach whereby the focus for research is that "migration constitutes an essential field of research that allows us to critically understand capitalism. There is no capitalism without migration, one could say, with the regime that attempts to control or tame the mobility of labor playing a strategic role in the constitution of capitalism and class relations" (Mezzadra 2011, 125). With that said, an emancipatory migration research paradigm is meant to be part of the struggle against state and capitalist repression and exploitation and considers borders scars on the body of Earth. Inspired by disability studies and the emancipatory research paradigm (cf. French and Swain 1997), I believe that critical and politically engaged research on migration needs to address and be evaluated against a number of principles that can be stated as questions:

1. Does the research promote migrants' control or scrutiny over the processes that shape their lives?

2. Does the research address the concerns of migrants themselves?

3 . Does the research support migrants in their struggle against oppression and for free mobility?

4. Does the research guarantee the safety and integrity of migrants?

Research on migration is unlikely to undergo any substantial change without more fundamental changes in the way migration and migrants are viewed within academia. Moving populations are being empowered by themselves and the political solidarity networks that support them. The question is, can migration researchers become part of that empowerment? This can raise significant critique within the academic community regarding the issue of political neutrality versus academic partisanship. Even for social constructivists, knowledge production must be protected by commitment to political values via the researcher's adoption of symmetrical and neutral stance. Instead, I view the research practice as part of complex networks of practices and struggles subject to power and economic relationships (May 1994). The researcher may be drawn in as a participant or used as a tool (Scott et al. 1990). Researchers 
have never been isolated from politics, as they have always engaged with diverse groups when conducting research and have returned their findings to these groups (Burawoy 2004). I advocate an emancipatory migration research paradigm that allies itself with struggles and solidarity movements related to migration and moving populations. Disability activist and academic Colin Barnes (2003), in a reflective paper about the impact of emancipatory disability research, argues that "research outcomes in themselves will not bring about meaningful political and social transformation, but they must reinforce and help stimulate further the demand for change. Hence, the main targets for emancipatory disability research are disabled people and their allies" (ibid., 13). Without involving migrants, their allies, and their political targets in this epistemological pursuit, we will merely reproduce academic hierarchies with researchers in the lead. In other words, when directly linked with migrants' ongoing struggle for free mobility, decent living conditions, open borders, papers for all, conducting emancipatory migration research can have a meaningful impact on the empowerment and policies affecting migrants' lives.

I see three lines of criticism here: (1) Can this be done? How can we involve migrants in configuring research agendas and how can we encourage the institutions that fund our research to support this idea? We need to acknowledge and learn from earlier examples of engaged or collaborative research (see for example Sillitoe 2016). The rich tradition and heritage of engaged scholarship must be translated into concrete methodological tools. Thus, it is not only an ontological issue about the empirics of our research but also about epistemological politics and how we as researchers challenge and change the criteria and borders of the political economy of scientific research by establishing practices, political agendas, and actions that create space for emancipatory research within our institutions. (2) Is this an overly Eurocentric approach? Indeed, the experiences and literature presented in this chapter are somewhat "European". I do not argue that this idea necessarily has a universal application. It is useful and compatible with such an approach to compare and juxtapose it to non-western narratives, epistemological politics, and methodological approaches related to migration research. It is more than imperative to queer our western privileged cultural and research capital in the context of doing emancipatory migration research. This is again an onto-epistemological game. As Sandro Mezzadra (2011) claims: "This is helpful not only in itself, but also in order to problematize the way in which we analyze migration in Europe and the 'west'; in order 
that we methodologically train and decenter our critical gaze" (122). (3) However, this would appear to be indirect recognition of scientific research as the only legitimate game in town? Are there any other ways to empower moving populations and conduct investigative work on migration? I do not recognise academic research as the only way to discursively and analytically support the struggles of migrants. We have a duty as political subjects and researchers not only to engage migrants in the research process but also to co-develop a new political epistemology of migrations that implies methods and ways to return and diffuse this knowledge to the migrants themselves.

Radical seminars and workshops in locations friendly to migrants, circulation through open media and popularisation of the knowledge acquired, online networks and discussion platforms, activists' meetings, websites to circulate counter-knowledge, and collective discussions (e.g. storiemigranti.org, bordermonitoring.eu, watchthemed.net, kritnet.org, migreurop.org) (see Casas-Cortes et al. 2015) are essential elements of an emancipatory migration research paradigm as well as the ways and suggestions proposed by migrants. This implies a mixed-method approach that not only includes scientific methodologies, such as documentation of experiences and barriers, monitoring and barometering of migrant grassroot struggles, alter-visualisation of counter-mapping, and the production of new concepts (ibid.), but also requires migrant-friendly practices, such as self-organisation and protection of moving populations, especially those without papers or those exposed to violence.

\section{Conclusion?}

This chapter did not intend to reinvent the wheel of methodological reflexivity for the role of the researcher. It constitutes an uproar built on personal reflections and emotions while doing fieldwork research for the DIGINAUTS project. These are common thoughts noted by numerous researchers in the field and several scholars have problematised them in a myriad of far more sophisticated ways than mine. This is my humble and perhaps uncensored effort to position myself in these debates. However, I failed in one of the major principles of writing an academic paper, that is, to pose as many questions as I can answer within the margins of the manuscript. But as I stated in the introduction, this chapter does not necessarily provide many answers. It certainly poses multiple questions that might be useful to colleagues, especially younger ones and those who 
are new to the hardship of conducting social scientific research concerning somewhat existential and political aspects of the research process. I questioned my role in terms of intersectional subjectivity and conducting research on migrants living in horrendous conditions. I asked about the compatibility of conducting (symmetrical/neutral) research while being a political subject in solidarity with the research subject. I questioned the triviality, the vulgarity, and relevance of the research topic considering the brutality of the living status of the "researched". I reflected upon the complexity of the topic and the values, interests, and politics embedded in the fieldwork. I pondered the efficiency of the research for the lives and well-being of migrants and the limits between action research and creating an academic career. I even questioned the point of this paper.

It was important to me to implicate, in a detailed and meticulous way, my own feelings in the description of the fieldwork, to add another blow to the picture of the researcher as an emotionless, neutral, symmetric creature. This fieldwork was mostly about emotions, my own and the migrants' and solidarians' with whom I met and interacted. I extensively and repeatedly referred to my emotion of shame and my researcher's role as redundant. I explained how my political loyalties clashed with my research activity, awakening a deep feeling of embarrassment for conducting what I perceived then as a research investigation that was meaningless for the migrants but valuable to my career. But as feminist and queer scholarship has shown that emotions play an important role in politics (Ahmed 2014), my feeling of shame also acted as a reminder of not only how power asymmetries in fieldwork shape the research, but also that emotions can trigger a conscious change in the epistemological balance of the research process. With this elevating reflection in mind, I turned to my previous experience with disability studies to gain inspiration for developing a politically engaged epistemology for migration studies. Paraphrasing the revolutionary slogan "action substitutes tears", epistemological and political solidarity with migrants substitutes feelings of shame. In the framework of this chapter, the emancipatory research paradigm of disability research acted as a template for developing four principles for a politically engaged migration studies epistemology. These principles align with efforts "to destabilize the binaries of researcher and researched, focusing instead on the identification or creation of spaces of engagement and proximity, sites of shared struggle and precarity. And they highlight the diverse practices by which mobile subjects negotiate 
and contest shifting forms of domination and exploitation" (Casas-Cortes et al. 2015).

This is not an easy task and several challenges remain to be addressed. The idea of an emancipatory migration research paradigm, as described above, is merely the first step towards such an ambitious goal, and this publication is not even close to a complete framework for a political epistemology of migration. Such a framework requires the translation of the rich experience of several migration scholars from the field into a systematised and politically informed epistemological agenda that includes the views and needs of migrants. This is a call for researchers who have faced similar dilemmas, emotions, and dead ends in the field to write future publications, and highlights the wish to engage in a research activity compatible with political solidarity with migrants. This embryonic idea and the four principles constitute a set of reflections and a basis for sparking this discussion. It is, after all, our academic and political duty to return to our research subjects the affluence of our research. This is my way to stay loyal to my own political principles and conduct research while performing solidarity with migrants.

\section{Notes}

1. According to Rozakou (2018), the term solidarian is a neologism. In the context of the latest migration flows to Greece, "the solidarian has turned from an adjective to a noun; this grammatical shift signifies the radicalisation of solidarity that took place in austerity-ridden Greece and the flourishment of solidarity. The diffusion of the notion is interrelated with the reconfiguration of the conceptions of the notions of 'social' that has taken place in the country. The expansion of solidarity, and solidarity with migrants in particular, is an essential element of the political content of sociality in this particular historical conjuncture" (ibid., 189). See also Sandberg, Mollerup and Rossi, Chapter 3 in this volume.

2. The hotspot solution was presented by the EU in the spring of 2015 as part of a larger policy push termed the European Agenda on Migration (European Commission 2015). The camps were initially implemented to enable identification, registration, and fingerprinting of arriving migrants, (Antonakaki et al. 2016). However, several researchers have addressed the multifunctional political role of the hotspot approach for the EU migration policy and the management of migratory flows.

3. The EU-Turkey Statement was signed in March 2016 to resolve the 2015 "migrant crisis" and despite critics, it is considered an efficient policy move 
that stands out as an exemplar solution for similar future developments (Delcker 2017).

4. It is not my intention here to disregard academic traditions, such as engaged anthroplogy (see for example the introduction in Engaged Anthropology-Views from Scandinavia) with important contributions on similar topics. This chapter aspires positioning itself in the larger community of engaged scholarship.

5. For a thorough discussion on the risks and benefits of publishing migration research results, see Düvell et al. (2010).

6. As in "lateral and anti-hierarchical relatedness [...] in contrast to both hospitality (the dominant cultural code of dealing with alterity) and bureaucratic frameworks of assistance to immigrants and refugees" (Rozakou 2018, 189). My understanding is that political solidarity does not constitute a humanitarian issue that will be resolved when the national state takes into consideration the human rights of migrants according to the liberal principles of the French revolution. Solidarity, in this context, refers to the horizontal gathering of disparate elements that enables the formation of a collective political movement (May 2013).

7. Several insurrectionary events have occurred in the Moria camp since its inauguration, which led to it being finally and totally burnt down in September 2020.

\section{BIBLIOGRAPHY}

Ahmed, Sara. 2014. Cultural Politics of Emotion. Edinburgh University Press.

Al Jazeera. 2018. "Rare Look at Life Inside Lesbos' Moria Refugee Camp." Retrieved from https://www.aljazeera.com/gallery/2018/1/19/rare-lookat-life-inside-lesbos-moria-refugee-camp.

Antonakaki, Melina, Bernd Kasparek, and Georgios Maniatis. 2016. "Counting Heads and Channeling Bodies: The Hotspot Center Vial in Chios, Greece, Report after Fieldwork.” Research Project Transit Migration 2.

Arendt, Hannah. 1951. The Origins of Totalitarianism. New York: Schocken Books.

Arendt, Hannah. 1972. Crises of the Republic: Lying in Politics, Civil Disobedience on Violence, Thoughts on Politics, and Revolution (Vol. 219). San Fransico, CA: Houghton Mifflin Harcourt.

Athens-Macedonian News Agency. 2019. "Greek Authorities Awaiting Coroner's Report on Asylum-Seeker's Death in Moria, Migration Min. Says." Retrieved from https://www.amna.gr/en/article/323142/Greek-authorities-awaitingcoroners-report-on-asylum-seekers-death-in-Moria--Migration-Min-says.

Badiou, Alan. 2004. "Fifteen Theses on Contemporary Art." Lacanian Ink 23. 
Balouziyeh, John. 2017. "Dispatch from Moria Refugee Camp: A Crisis within a Crisis." Available at SSRN 3152178.

Barnes, Colin. 2003. "What a Difference a Decade Makes: Reflections on Doing 'Emancipatory' Disability Research.” Disability and Society 18 (1): 3-17.

Black, Richard. 2001. "Fifty Years of Refugee Studies: From Theory to Policy." International Migration Review 35 (1): 57-78.

Burawoy, Michael. 2004. "The World Needs Public Sociology." Sosiologisk tidsskrift 12 (3): 255-272.

Casas-Cortes, Maribel, Sebastian Cobarrubias, Nicolas De Genova, Glenda Garelli, Giorgio Grappi, Charles Heller, Sabine Hess, Bernd Kasparek, Sandro Mezzadra, Brett Neilson, and Irene Peano. 2015. "New Keywords: Migration and Borders." Cultural Studies 29 (1): 55-87.

Clifford, James, and George E. Marcus. 1986. Writing Culture: The Poetics and Politics of Ethnography. Berkeley: University of California Press.

Colson, Nicole. 2017. "Despair in Europe's Refugee Camps.” Green Left Weekly (1132), 13 .

De Genova, Nicolas, ed. 2017. The Borders of "Europe": Autonomy of Migration, Tactics of Bordering. Durham, NC: Duke University Press.

Delcker, J. (2017, July 28). "Architect of EU-Turkey refugee pact pushes for West Africa deal." Retrieved March 20, 2021, from POLITICO website: https://www.politico.eu/article/migration-italy-libyaarchitect-of-euturkey-refugee-pact-pushes-for-west-africa-deal/.

Deutsche Welle. 2019. "Lesbos: Hellish Conditions for Refugees in Moria." Retrieved from https://www.dw.com/en/lesbos-hellish-conditionsfor-refugees-in-moria/a-50384674.

D'Haenens, Leen, Willem Joris, and François Heinderyckx. 2019. Images of Immigrants and Refugees in Western Europe. Leuven: Leuven University Press.

Düvell, Franck, Anna Triandafyllidou, and Bastian Vollmer. 2010. "Ethical Issues in Irregular Migration Research in Europe." Population, Space and Place 16 (3): 227-239.

European Commission. 2015. The hotspot approach to managing exceptional migratory flows.

Farkas, Johan, Janick Schou, and Christina Neumayer. 2018. "Platformed Antagonism: Racist Discourses on Fake Muslim Facebook Pages." Critical Discourse Studies 15 (5): 463-480.

Fekete, Liz. 2018. "Migrants, Borders and the Criminalisation of Solidarity in the EU." Race and Class 59 (4): 65-83.

Foley, Douglas E. 2002. "Critical Ethnography: The Reflexive Turn." International Journal of Qualitative Studies in Education 15 (4): 469-490.

French, Sally, and Swain, John. 1997. "Changing Disability Research: Participating and Emancipatory Research with Disabled People." Physiotherapy 83 (1): 26-32. 
Fujimura, John. 1991. "On Methods, Ontologies and Representation in the Sociology of Science: Where Do We Stand?" In Social Organization and Social Process: Essays in Honor of Anselm Strauss, edited by D. Maines, 207-249. New York: De Gruyter.

Galis, Vasilis. 2006. From Shrieks to Technical Reports: Technology, Disability and Political Processes in Building Athens Metro. Linköping University Studies in Arts and Science No. 374. PhD thesis, Linköping University, Sweden.

Galis, Vasilis, and Anders Hansson. 2012. "Partisan Scholarship in Technoscientific Controversies: Reflections on Research Experience." Science as Culture 21 (3): 335-364.

Gordon, Eleanor, and Henrik K. Larsen. 2020. “'Sea of Blood': The Intended and Unintended Effects of the Criminalisation of Humanitarian Volunteers Rescuing Migrants in Distress at Sea." Disasters.

Gray, Breda. 2008. "Putting Emotion and Reflexivity to Work in Researching Migration." Sociology 42 (5): 935-952.

The Guardian. 2019. "Oxfam Condemns EU over 'Inhumane' Lesbos Refugee Camp." Retrieved from https://www.theguardian.com/world/2019/jan/ 09/oxfam-criticises-eu-inhumane-lesbos-refugee-camp-moria.

The Guardian. 2020. "Moria Is a 'Hell': New Arrivals Describe Life in a Greek Refugee Camp." Retrieved from https://www.theguardian.com/global-dev elopment $/ 2020 /$ jan/17/moria-is-a-hell-new-arrivals-describe-life-in-a-greekrefugee-camp.

Haraway, Donna. 2001. "Situated Knowledges: The Science Question in Feminism and the Privilege of Partial Perspective." In The Gender and Science Reader, edited by M. Lederman and I. Bartsch, 169-188. London: Routledge.

Honig, Bonnie. 2009. Emergency Politics: Paradox, Law, Democracy. Princeton: Princeton University Press.

Jørgensen, Martin Bak. 2012. "Categories of Difference in Science and Policy-Reflections on Academic Practices, Conceptualizations and Knowledge Production." Qualitative Studies 3 (2): 78-96.

Lind, Jacob. 2020. The Politics of Undocumented Migrant Childhoods: Agency, Rights, Vulnerability. Doctoral dissertation, Malmö University.

Lundberg, Anna, and Emma Söderman. 2015. "Reflections on the Right to Health." In Social Transformations in Scandinavian Cities: Nordic Perspectives on Urban Marginalization and Social Sustainability, edited by E. Righard, M. Johansson, and T. Salonen, 251-264. Nordic Academic Press.

Lundberg, Anna, and Michael Strange. 2017. "Who Provides the Conditions for Human Life? Sanctuary Movements in Sweden as Both Contesting and Working with State Agencies." Politics 37 (3): 347-362.

Lury, Celia, and Nina Wakeford, eds. 2012. Inventive Methods: The Happening of the Social. Routledge. 
Mackenzie, Adrian. 2012. "Set." In Inventive Methods: The Happening of the Social, edited by C. Lury and N. Wakeford, 219-231. London: Routledge.

Marres, Noortje. 2012. "The Experiment in Living." In Inventive Methods: The Happening of the Social, edited by C. Lury and N. Wakeford, 76-95. Routledge.

May, Todd. 1994. The Political Philosophy of Poststructuralist Anarchism. University Park, PA: The Pennsylvania State University Press.

May, Todd. 2013. "Humanism and Solidarity." Parrbesia 18: 11-21.

Mezzadra, Sandro. 2011. "The Gaze of Autonomy: Capitalism, Migration and Social Struggles." In The Contested Politics of Mobility: Borderzones and Irregularity, edited by Vicki Squire, 121-142. Routledge.

Millner, Naomi. 2011. 'From 'Refugee' to 'Migrant' in Calais Solidarity Activism: Re-staging Undocumented Migration for a Future Politics of Asylum." Political Geography 30 (6): 320-328.

New York Times. 2018. “'Better to Drown': A Greek Refugee Camp's Epidemic of Misery." Retrieved from https://www.nytimes.com/2018/10/02/world/ europe/greece-lesbos-moria-refugees.html.

No Border Kitchen. 2019. "In Memory and Rage." Retrieved from https://nob orderkitchenlesvos.noblogs.org/post/2019/01/.

Nordstrom, Carolyn, and Antonius C. Robben, eds. 1995. Fieldwork under Fire: Contemporary Studies of Violence and Culture. University of California Press.

Oliver, Mike. 1992. "Changing the Social Relations of Research Production?" Disability, Handicap and Society 7 (2): 101-114.

Pittaway, Eileen, Linda Bartolomei, and Richard Hugman. 2010. “'Stop Stealing Our Stories': The Ethics of Research with Vulnerable Groups." Journal of Human Rights Practice 2 (2): 229-251.

Pitzer, Andrea. 2017. One Long Night: A Global History of Concentration Camps. Hachette, UK.

Reuters. 2019. "'Moria Is Hell': Asylum Seekers Protest Conditions at Greek Camp." Retrieved from https://www.reuters.com/article/uk-europemigrants-greece-lesbos-protest-idUKKBN1WG3WA.

Robben, Antonius. 1995. "The Politics of Truth and Emotion among Victims and Perpetrators of Violence." In Fieldwork Under Fire: Contemporary Studies of Violence and Culture, edited by C. Nordstrom, and A. C. Robben, 81-103. University of California Press.

Rozakou, Katerina. 2017. "Solidarity\# Humanitarianism: The Blurred Boundaries of Humanitarianism in Greece." Etnofoor 29 (2): 99-104.

Rozakou, Katerina. 2018. "Solidarians in the Land of Xenios Zeus: Migrant Deportability and the Radicalisation of Solidarity." In Critical Times in Greece: Anthropological Engagements with the Crisis, edited by D. Dalakoglou and G. Agelopoulos, 188-201. Routledge. 
Scott, Pam, Evelleeen Richards, and Brian Martin. 1990. "Captives of Controversy: The Myth of the Neutral Social Researcher in Contemporary Scientific Controversies." Science, Technology and Human Values 15 (4): 474-494.

Sillitoe, Paul, ed. 2016. Indigenous Studies and Engaged Anthropology: The Collaborative Moment. Routledge.

Spivak, Gayatri Chakravorty. 1988. "Can the Subaltern Speak?" In Marxism and the Interpretation of Culture, edited by C. Nelson and L. Grossberg, 271-313. Urbana, IL: University of Illinois Press.

Ticktin, Miriam. 2014. "Transnational Humanitarianism." Annual Review of Anthropology 43: 273-289.

Ticktin, Miriam. 2017. "A World without Innocence." American Ethnologist 44 (4, November): $577-590$

Titley, G. 2019. Racism and Media. Sage.

Turton, David. 1996. "Migrants and Refugees: A Mursi Case Study." In In Search of Cool Ground: War, Flight and Homecoming in Northeast Africa, edited by Tim Allen, 96-110. London: Africa World Press.

Tyler, Imogen. 2006. "Welcome to Britain': The Cultural Politics of Asylum." European Journal of Cultural Studies 9 (2): 185-202.

Vandevoordt, Robin. 2019. "Subversive Humanitarianism: Rethinking Refugee Solidarity Through Grass-Roots Initiatives." Refugee Survey Quarterly 38 (3): 245-265.

Van Liempt, Ilse, and Veronika Bilger, eds. 2009. The Ethics of Migration Research Methodology: Dealing with Vulnerable Immigrants. Sussex Academic Press.

Van Liempt, Ilse, and Veronika Bilger. 2018. "Methodological and Ethical Dilemmas in Research Among Smuggled Migrants." In Qualitative Research in European Migration Studies, 269-285. Cham: Springer.

Venkatesh, Sudhir Alladi. 2013. "The Reflexive Turn: The Rise of First-Person Ethnography." The Sociological Quarterly 54 (1): 3-8.

Žižek, Slavoj. 2008. Violence: Six Sideways Reflections. London: Profile books. 
Open Access This chapter is licensed under the terms of the Creative Commons Attribution 4.0 International License (http://creativecommons.org/licenses/ by $/ 4.0 /$ ), which permits use, sharing, adaptation, distribution and reproduction in any medium or format, as long as you give appropriate credit to the original author(s) and the source, provide a link to the Creative Commons license and indicate if changes were made.

The images or other third party material in this chapter are included in the chapter's Creative Commons license, unless indicated otherwise in a credit line to the material. If material is not included in the chapter's Creative Commons license and your intended use is not permitted by statutory regulation or exceeds the permitted use, you will need to obtain permission directly from the copyright holder.

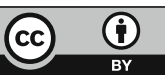

